\title{
La alfabetización mediática e informacional: injerencia y perspectiva en América Latina. Entrevista con Guillermo Orozco, investigador en comunicación
}

\author{
Media and information literacy: interference and perspective in \\ Latin America. Interview with Guillermo Orozco, researcher in \\ communication
}

Erika Lucía González Carrión

Universidad Nacional de Loja

\begin{abstract}
Resumen
Guillermo Orozco es un reconocido académico mexicano, Doctor en Educación por la Universidad de Harvard, miembro emérito del Sistema Nacional de Investigaciones y coordinador de la Cátedra de Alfabetización Mediática Informacional y Diálogo Intercultural (Universidad de Guadalajara y UNESCOUNAOC (United Nations Alliance of Civilizations). Ha desarrollado estudios de recepción y alfabetización audiovisual, enfocándose en la producción, mediación y las estrategias pedagógicas de intervención con los medios, especialmente la televisión. Sus aportaciones son una referencia para los profesionales de la comunicación y educación en América Latina. Es autor y coautor de numerosos libros, entre los que destacan: Televisión y producción de significados (1994), Audiencias, Televisión y Educación (2001), Recepción y mediaciones (2002), La televisión de proximidad en el entorno transmedia (2017), etc.
\end{abstract}

Palabras clave: Alfabetización mediática; Educación; Tecnología; Enseñanza; Aprendizaje

\begin{abstract}
Guillermo Orozco is a renowned Mexican academic, Doctor of Education (Harvard University), emeritus member of the National Research System and coordinator of the Chair of Informational Media Literacy and Intercultural Dialogue (University of Guadalajara and UNESCO-UNAOC (United Nations Alliance of Civilizations He has developed audio-visual reception and literacy studies, focusing on production, mediation and pedagogical intervention strategies with the media, especially television. His contributions are a reference for communication and education professionals in Latin America. He has authored and co-authored a number of books, among which: Television and production of meanings (1994), Audiences, Television and Education (2001), Reception and mediations (2002), Proximity television in the transmedia environment (2017), etc.
\end{abstract}

Keywords: Media literacy; Education; Technology; Teaching; Learning 
Me gustaría agradecer al Dr. Guillermo Orozco por brindarme este valioso espacio para intercambiar conocimientos en pro de difundir un conocimiento científico y validado sobre la alfabetización mediática informacional, para una mejor comprensión de sus efectos en América Latina y sus posibles mejoras de inserción dentro de las aulas de clase y fuera de ella, como un recurso para potenciar la educación y contribuir a una formación adaptada a las necesidades del siglo XXI. Por medio de la presente entrevista se busca determinar y exponer todas las estrategias que pueden emplear los docentes latinoamericanos para introducir la tecnología dentro del proceso de enseñanza y aprendizaje y así empezar a utilizar las plataformas digitales como aliadas de la educación, antes que como entorpecedoras de la misma. Dentro del continente latinoamericano las deficiencias respecto a la alfabetización mediática y la información son latentes y requieren la puesta en marcha de un conjunto de estrategias para introducir sistemas tecnológicos en las aulas de clase, al punto de formar ciudadanos con la suficiente capacidad de discernimiento y análisis al contenido que reciben en todo momento por parte de los medios de comunicación, sean estos tradicionales o digitales. Además, el continente tiene el gran reto de formar ciudadanos con una mirada analítica, con suficiente desenvolvimiento para emitir juicios críticos argumentados sobre la información que reciben a diario. La alfabetización mediática es pieza fundamental para una sociedad más crítica, democrática y acoplada a un mundo globalizado, que forme ciudadanos con la suficiente capacidad para discernir los contenidos que observan y cuestionar todo aquello que le rodea a nivel mediático.

Entrevistadora: ¿Cómo cataloga y define a la alfabetización mediática?

Orozco: La definiría como un conjunto de esfuerzos encaminados a capacitar a todos los que utilizamos medios y tecnologías de información para tener una interacción mucho más crítica y a la vez productiva con todos los medios disponibles.

Entrevistadora: ¿Cómo observa la alfabetización mediática en América Latina? Porque si bien es cierto que la alfabetización mediática está tomando pasos agigantados en Europa América del Norte o Australia,¿qué sucede particularmente en Latinoamérica?

Orozco: En América Latina existen varias etapas históricamente. En el comienzo la alfabetización mediática se entendía más como una capacitación ideológica para que los jóvenes supuestamente enfrentaran los mensajes de la televisión que venían de Estados Unidos y eran capitalistas, entonces se entendía como una capacitación en estudiar el marxismo o historia crítica, para que pudiéramos hacer 
el enfrentamiento y no se dañaran los mensajes. De ese planteamiento a la fecha ha pasado por distintos énfasis: la alfabetización crítica, luego fue la lectura crítica, recepción de los medios, lectura crítica de los medios, formación de audiencias críticas para el intercambio con los mensajes, y actualmente, se está utilizando mucho en todo Iberoamérica el tema de competencias mediáticas, en parte como propuesta de Ignacio Aguaded.

Es el momento en donde estamos, pero habría que decir que existió un crecimiento diferenciado entre el desarrollo y proliferación de la alfabetización en América Latina y el resto del mundo; en el resto del mundo se creía originalmente que la alfabetización mediática era desarrollar las destrezas para poder enfrentar los medios y después lo referente a computadoras y tecnologías de la información, sin fundamento crítico ni nada, más bien como un adiestramiento. Era concebido como algo instrumental y ahí tuvieron muchas diferencias los latinoamericanos y los europeos sobre todo con los ingleses, canadienses y franceses. Finalmente, la UNESCO (Organización de las Naciones Unidas para la Educación, la Ciencia y la Cultura) aceptó hablar de dos cosas: de alfabetización entendiendo la parte instrumental y crítica eventualmente, pero también la parte reflexiva, crítica e informacional para trabajar todo lo que va más allá de los medios y que se vincula con las tecnologías informativas. Esta combinación de una alfabetización mediática e informacional es lo que la UNESCO patrocina y promueve, entendiendo no solo el adiestramiento técnico para un manejo que permita estar en redes y demás, sino también el pensamiento crítico para analizar, buscar y tomar posición frente a los mensajes con los que estamos interactuando.

Entrevistadora: Muy de acuerdo Doctor, entonces tomando el término que usted ha empleado "alfabetización mediática e informacional", ¿̇usted cree que ya existe una normalización de este tipo de modelos en América Latina?

Orozco: Definitivamente que no, pero sÍ siento que se va expandiendo un poco. Por ejemplo, en Colombia está el concepto de la UNESCO, en Brasil también y en México lo estamos haciendo, en parte porque tenemos en estos tres países conexiones directas y fuertes con la UNESCO. Tenemos programas que funcionan como Cátedras UNESCO en combinación con la otra instancia grande de la ONU (Organización de Naciones Unidas) relacionada al desarrollo de las civilizaciones y las culturas, entonces hay un programa en el que estoy yo, una colega brasileña y otro colega colombiano, que trabajamos no solo con el término de AMI (Alfabetización Mediática Informacional), sino también con el desarrollo de una integración entre las culturas. 
Entrevistadora: En ese sentido, en el contexto de una universidad pública y con años de antigüedad dentro de un país latinoamericano, ¿qué posibilidades considera usted que hay de implementar un programa de alfabetización mediática e informacional (ya sea para los estudiantes propios de la universidad, docentes o público externo, trabajando en conjunto con cursos de formación continua o a través de la UNESCO)?

Orozco: Creo que se puede contactar a la UNESCO. Concretamente para América Latina Hispana yo soy el contacto formal con la UNESCO y si una universidad quiere vincularse se realiza una carta de intención que es enviada a mi persona (firmada por la cabeza del proyecto y una autoridad de la universidad interesada), de manera informal y sin pasar por rectoría para evitar toda la burocracia de las universidades. Entonces se realiza un acuerdo por escrito para que quienes formen parte del proyecto, especialmente quien lo preside, se sumen a la Cátedra UNESCO que yo coordino acá en México. Esto yo lo doy a conocer a UNESCO y en un par de años ya se adquiere el vínculo directo con la entidad, por la parte de alfabetización mediática informacional. Entonces el primer paso para una universidad de América Latina es establecer el contacto con el programa que yo coordino acá en México y, a partir de este punto, se realiza una entrada preliminar antes de tener un programa propio en la universidad interesada.

La universidad tendría un reconocimiento de pertenecer a una red de universidades, lo que permitiría obtener un financiamiento para asistir a alguna reunión o actividad planteada en torno al tema de la alfabetización mediática e informacional. Estas redes son un aliciente para poder intercambiar conocimientos y montar una propuesta o taller para alumnos o para docentes, para conocer qué piensan sobre este tema. Existe un problema con los docentes que creen que todo lo relacionado a medios y tecnología puede perjudicar el proceso de enseñanza dentro del aula, en lugar de aprovechar por ejemplo el teléfono celular para hacer investigaciones o ingresar a determinados sitios. Se observa que algunos docentes impiden que los alumnos ingresen con el teléfono celular a clases. Pero hay que trabajar ahí la comprensión de la tecnología por parte de los docentes, como una posible aliada para sus objetivos de aprendizaje dentro del aula y eso sería algo muy importante. En América Latina, los docentes consideran que la tecnología no debe ingresar al salón de clase porque es pura diversión y distracción de los alumnos y perjudica el proyecto o currículo que tienen que enseñar, en vez de buscar las maneras de ayudarse de la tecnología o del interés que tienen los alumnos por el celular, sobre todo para cumplir los propósitos de su clase. En un plan de trabajo como capacitación se debe empezar por los docentes para que, si bien vean el 
peligro de la tecnología, también sean conscientes de la necesidad de ser alfabetizados para distinguir los engaños y la información que viene de redes sociales y a la vez conocer el potencial de la tecnología (especialmente el teléfono celular) como un recurso didáctico para la clase.

Entrevistadora: Exactamente, y como usted lo ha mencionado, en muchas ocasiones los docentes tienden a satanizar a la tecnología y por eso no la implementan a través de técnicas tan efectivas como la gamificación. Que importante sería que el docente tome ventaja de estas tecnologías y las pueda aprovechar al máximo con los estudiantes. Sobre esto doctor y de forma general, ¿cómo considera usted los niveles de alfabetización mediática en América Latina, hablando específicamente de docentes universitarios?

Orozco: Yo diría que bastante bajo, porque hay mucho por hacer en cada ciudad y en cada escuela. Yo creo que en general la alfabetización mediática e informacional requiere de ser fortalecida muchísimo. Si bien se tiene una primera capacitación instrumental para saber utilizar redes sociales y toda esta tecnología, no se tiene conciencia de los peligros que hay al estar expuestos y poner nuestras imágenes o sentimientos a circular en redes como si no pasara nada. Hay una necesidad de capacitar a todos para ver los peligros de las redes, sin llegar a satanizarlas de ninguna forma, pero sí siendor conscientes de los peligros que acechan en estos entornos. Es muy importante también el trabajar con la alfabetización mediática con maestros y estudiantes a la par, además de las familias, que también son parte importante de todo este proceso.

Entrevistadora: A su criterio, ¿usted encuentra necesario que se imparta alfabetización mediática a la ciudadanía en general? Ya no hablando netamente de universidades, sino del conglomerado social, en vista de su necesidad apremiante. Particularmente en este caso ¿De quién es la responsabilidad?

Orozco: Es una pregunta difícil, pero la responsabilidad estaría en la ciudadanía joven. Para quienes están en la escuela o la universidad, sería la institución educativa de la que forman parte la responsable. Pero para quienes salieron de la instrucción formal y no están dentro del ámbito educativo, no está claro quién tendría la competencia concreta de realizarlo, quizá su lugar de trabajo, de organizar grupos de vecinos, en fin, la responsabilidad ya es de los propios ciudadanos.

Entrevistadora: Correctamente. Volviendo a las instituciones educativas (escuelas, colegios, universidades), ¿usted considera que la alfabetización mediática informacional tiene el suficiente peso pedagógico dentro de las carreras, currículos 
y mallas educativas, o aún se puede hacer un poco más estrechando lazos con Ministerios de Educación de los diferentes países como una posible alternativa?

Orozco: Totalmente de acuerdo, la alfabetización mediática no tiene el lugar, conexión o valoración adecuados y creo que por eso es importante trabajar para que, desde los Ministerios de Educación, se pueda trabajar o apoyar un programa de capacitación docente en tecnologías de la información y en medios. Así esto vendría de arriba, de la autoridad máxima. En todos los países los maestros son un gremio y la autoridad máxima es el Ministerio de Educación; las relaciones entre ambas partes no siempre son las mejores. En México, por ejemplo, han sido muy conflictivas, pero hay que ingresar por ambos sectores en pro de una mejor alfabetización, ya sea por los maestros y también por el Ministerio, para que este modifique los currículos introduciendo la capacitación en el ámbito mediático e informacional de los estudiantes y ofrecer cursos para que los maestros se capaciten. Hay que convencer a los directores de los sindicatos magisteriales para que implanten estas nuevas competencias en sus programas, porque caso contrario se quedarían atrás en el desarrollo del mundo. Se dice fácil, pero es muy complicado. Se trata de trabajar en ambos lugares, ministerios y sindicatos de docentes, es un trabajo político que se debe realizar.

Entrevistadora: Porque caso contario, como usted muy bien lo ha afirmado, nos quedamos a la deriva y con niveles muy bajos de competitividad frente a otros profesionales. Yo formo parte de la red Alfamed joven (Red Interuniversitaria Euroamericana de Investigación Sobre Competencias Mediáticas para la Ciudadanía), del Dr. Ignacio Aguaded, de España. ¿Qué beneficios puede traer una red interuniversitaria de investigación en este campo dirigida como lo reitero a los más jóvenes?

Orozco: Creo que es el situar el tema de alfabetización mediática en la mente de todos los que estamos vinculados con las universidades. A mi parecer, es muy importante que, desde una institución con el prestigio y trayectoria que está adquiriendo Alfamed a nivel Iberoamericano, se empiece a tratar de hacer accesible a las universidades y a las instituciones educativas materiales concretos para avanzar en el tema de la alfabetización mediática. No ha habido materiales y los pocos existentes han sido esporádicos en algún momento, país o sector del ámbito educativo. Lo que hace falta es algo más consistente y global. Entonces creo que Alfamed tiene que aprovechar esa parte de ofrecer materiales, como es el caso de UNESCO que los ofrece traducidos a varios idiomas. La necesidad de este momento no es tanto de iniciativas y de materiales para consultar, sino de introducir la idea de que una educación hoy y en el futuro no puede hacerse sin una alfabetización mediática e 
informacional. Ninguna educación básica estaría completa ni debería prescindir de la alfabetización informacional, porque se estaría prescindiendo de una herramienta con gran valor para los alumnos.

Entrevistadora: Por último, ¿qué líneas de mejora o propuestas se pueden implementar para perfeccionar las formas de alfabetización mediática e informacional contemporánea? ¿Qué nos puede sugerir para desde la escuela unir la alfabetización mediática, aspectos pedagógicos y demás?

Orozco: Yo diría que en primer lugar el criterio debería ser de una pedagogía lúdica, no puede ser una cosa dogmática. Yo hice un proyecto hace casi diez años en escuelas secundarias que se llamó "El laboratorio de televisión en la escuela". Puse televisores en la escuela y conseguí que los directores de estas escuelas públicas me asignaran un momento (los viernes, dos horas) para ver televisión dentro del aula, que fue mi primer objetivo, el que se perdiera el miedo a ingresar la televisión dentro del aula. El segundo objetivo era ver un programa con los estudiantes una hora y en la segunda hora comentar diferentes aspectos a partir de ese programa. Era el programa que había en ese momento, drama, ficción, telenovela, noticias, lo que fuera. El hecho era ir variando y que fueran viendo de manera consciente. Los profesores no estaban capacitados, pero en este proceso conjunto salían preguntas, respuestas, había que empezar a pensar, comentar lo que vieron. Estaban todos con una expectativa, no era estar tirados en el piso, sino con su mente trabajando, pensando lo que veían; no había ninguna doctrina, podían comentar lo que fuera.

El profesor lo único que tenía que hacer era reunir todas las ideas y explicarles lo que acababan de ver, en qué consistía, si existían acuerdos o no y ver su reacción o sus diferentes impresiones. Esto es poner al educando de secundaria y de último año de primaria (que estaban incluidos dentro del proyecto) a plantarse frente a la pantalla, consciente de ver lo que pasa, porque tiene el reto de contarlo luego, no de si pensó bien o entendió bien, importa solo la actitud de estar atento, pensar y repensar, es decir, dar una vuelta a la información que se recibe. Esto era mi objetivo mayor, romper esta negativa en los maestros de hablar de la televisión, que consistía en el principal enemigo de los maestros en América Latina. Los maestros me decían que todo el trabajo que se hacía en la escuela, la televisión lo quitaba en la casa, y a mi punto de vista es una exageración porque se sataniza y maldice a la televisión dentro de un ámbito educativo sin un fundamente sólido o una argumentación válida; hay que agarrar la televisión e ingresarla al salón de clases, hay que ver, comentarla porque es un gran avance respecto a la actitud de todos los que se están formando frente a las pantallas, de forma distinta y consciente. 
Ejemplos tan sencillos como estos es necesario implementar dentro de América Latina; países como España han trabajado más y tienen un trabajo más avanzado en las escuelas, con planes de estudios más detallados para cada año de primaria o secundaria, lo que significa una diferencia muy grande con Latinoamérica, en lo que respecta a la inserción de medios dentro de la escuela y su aprovechamiento como un potencial recurso para mejorar la formación de cada uno de los estudiantes en congruencia con el entorno donde se desenvuelven.

\section{ERIKA LUCÍA GONZÁLEZ CARRIÓN}

Doctora del Programa de Doctorado Interuniversitario en Comunicación de la Universidad de Huelva (Media Literacy). Máster Interuniversitario en Comunicación y Educación Audiovisual por la UNIA y la Universidad de Huelva. Licenciada en Comunicación Social y Licenciada en Ciencias de la Educación con mención en Idioma Inglés.

erikalucia@hotmail.es https://orcid.org/0000-0003-3808-5460

González Carrión, E. L. (2021). La alfabetización mediática e informacional: injerencia y perspectiva en América Latina. Entrevista con Guillermo Orozco, investigador en comunicación. Bellaterra Journal of Teaching \& Learning Language \& Literature, 14(3), e941. https://doi.org/10.5565/rev/jtl3.941 